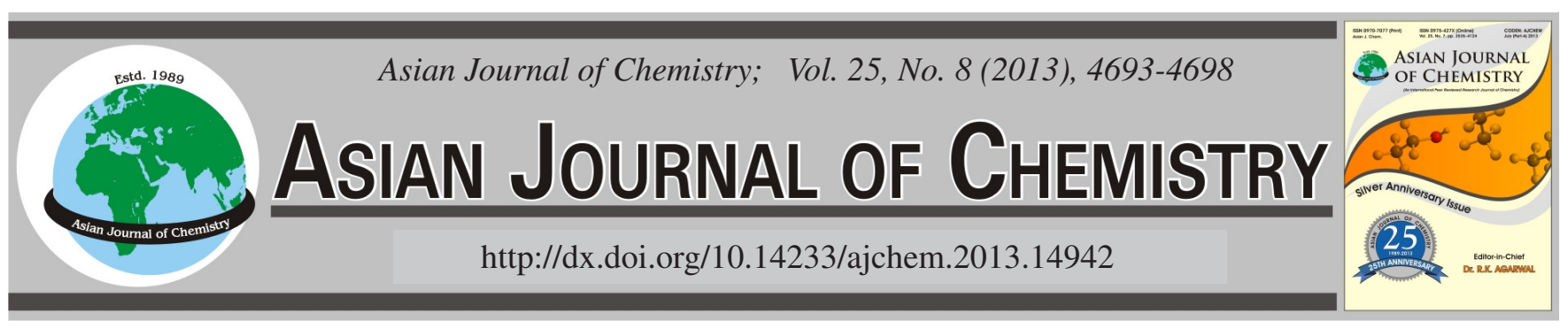

\title{
Adsorptive Removal of Dyes Using Crude Tree Barks: Equilibrium Isotherm and Kinetics
}

\author{
Olcayto KesKinKan ${ }^{*}$ and BehZAt BaLCi
}

Department of Environmental Engineering, Faculty of Engineering and Architecture, Cukurova University, 01330 Balcali/Adana, Turkey

*Corresponding author: E-mail: olcayto@cu.edu.tr

(Received: 8 December 2012;

Accepted: 22 February 2013)

AJC-13046

\begin{abstract}
In this paper, the adsorptive removal of dyes (basic violet 3-BV3 and acid red 360-AR360) commonly used in various industries was investigated using Eucalyptus camaldulensis barks as an alternative tertiary treatment material. Adsorption equilibria were attained at 20 and $80 \mathrm{~min}$ for various initial BV3 and AR360 concentrations (in the range 20-320 mg/L). Attempts were made to fit the equilibrium data obtained using the Langmuir, Freundlich, Temkin and Dubinin-Radushkevich adsorption isotherm models. The data obtained from the E. camaldulensis studies provided very strong correlation using the Langmuir, Freundlich and Dubinin-Radushkevich adsorption isotherms models with regression coefficient $\left(\mathrm{R}^{2}\right)$ values of $0.9763,0.9837,0.9955$ for BV3, 0.9989, 0.9915, 0.9725 for AR360, respectively. Evaluation of the experimental data using the Langmuir equation revealed that the maximum adsorption capacities of $E$. camaldulensis barks were 40.98 and $37.59 \mathrm{mg} / \mathrm{g}$ for BV3 and AR360, respectively. The dimensionless constant separation factor of the adsorbent/ adsorbate system was determined. External mass transfer was fast for BV3. Since BV3 was almost completely removed in 5 min, calculating | the intra-particle diffusion constant $\left(\mathrm{k}_{\mathrm{id}}\right)$ of BV3 is not advisable. Application of the pseudo second-order kinetic model was more logical for BV3 data and second order kinetic model was best fit for AR360 data.
\end{abstract}

Key Words: Eucalyptus camaldulensis barks, Dye removal, Adsorption isotherms, Kinetics.

\section{INTRODUCTION}

In the last decade, there has been an increasing concern on the pollution of aquatic environment. Effluents discharged from dyeing processes in various industries contain high colour and they contribute to water deterioration enormously. Their existence and treatment are the subject of discussion and environmental regulations in many countries ${ }^{1}$. Turkey has also recently included colour as a discharge parameter into the environmental regulations for wastewater discharges into the receiving streams. Dyes used in the textile industry are mostly synthetic, typically derived from coal tar and petroleum-based intermediates. Each dyeing process requires different amount of dye per unit of fabric to be dyed ${ }^{2}$. The high level of production and extensive use of dyes worldwide generate coloured wastewaters, which cause environmental pollution. Unless properly treated, these dyes in the wastewater discharges, whether treated or not, may significantly affect aquatic life through reduced photosynthetic activity due to diminished light penetration as well as toxicity ${ }^{3}$. In addition, many dyes and pigments are toxic and have carcinogenic and mutagenic effects ${ }^{4}$. Therefore, wastewaters which contain such dyes and their metabolites must be removed using proper treatment methods prior to discharge to receiving water bodies.
$\mathrm{BV} 3$, a protein dye, is used to identify the bloody fingerprints. BV3 is also used on most types of adhesive tapes for latent printing. It is also used in Gram's stain for the demonstration and primary classification of dyes. The brilliant colours can be produced using BV3. BV3 is toxic and may cause cancer, severe eye irritation and therefore, is harmful through inhalation, ingestion and through skin contact. Hence, the dye removal from effluents becomes essential ${ }^{5}$. AR360, on the other hand, are commonly used for dyeing carpets, cottons and other textile materials. AR360 also contain azo $(-\mathrm{N}=\mathrm{N}-)$ groups.

Because of their persistence to conventional wastewater treatment methods, certain researchers have focused on azo dyes ${ }^{6,7}$. Depending on the properties of the dyes and their wide range of application mentioned above, BV3 and AR360 were selected as indicator compounds for estimating the adsorption capacity of the tree materials used in the present study. The methods generally used for treating dye-containing wastewaters are membrane filtration, coagulation-flocculation ${ }^{8}$, reverse osmosis $^{9}$ and adsorption ${ }^{10}$. Adsorption is a widely-used and effective physical method for the treatment of coloured wastewater.

The most convenient method for designing adsorption systems is through adsorption isotherms. The theoretical adsorption capacity of an adsorbent for a particular contaminant 
can be determined by calculating its adsorption isotherm ${ }^{11}$. Thus, the performance of a given adsorption system can be demonstrated through their use. The degree to which adsorption will occur and the resulting equilibrium relationships are correlated according to the empirical relationship of Freundlich and the theoretically derived Langmuir relationship. Activated carbon is one of the most popular and widelyused adsorbents. In most industries, activated carbon is used for the treatment of toxic, non-biodegradable process effluents and as tertiary treatment following biological oxidation ${ }^{12}$. However, the application of adsorption processes for wastewater treatment is expensive because of the chemicals required for their regeneration after pollutant removal. The higher the effluent quality, the greater the cost. Studies are being carried out in order to replace activated carbon with low-cost alternatives and to utilize various waste products as novel adsorbents and, so far, many have been found to be applicable such as tree barks ${ }^{13,14}$.

Although the contribution of tree barks to wastewater treatment is already known, there is less literature information on the dye adsorption capacity of Eucalyptus barks in a batch system. More importantly, there is scarce literature on the $E$. camaldulensis barks among the adsorption studies. The determination of the dye adsorption capability of E. camaldulensis barks may contribute to system design approaches for adsorption systems to treat dye-containing wastewaters. Data from this adsorption study can also be incorporated into pilot and full-scale applications through determination of the adsorption characteristics of the tree barks of interest.

In the southern region of Turkey, E. camaldulensis is very common. Since the E. camaldulensis barks are almost costfree and only the transportation cost is involved for their possible use in tertiary wastewater treatment. The main purpose of this study was to determine the dye adsorption capacity of E. camaldulensis barks and contribute to the studies on the removal of dyes with tree barks.

\section{EXPERIMENTAL}

Adsorbent: E. camaldulensis barks were collected from their respective trees on the campus of Cukurova University in Adana, Turkey. Large evergreen E. camaldulensis trees are at a height of 24-40 m and their stout trunks are often short and crooked up to $2 \mathrm{~m}$ in diameter with open crown, widely spreading and irregular. Their barks are smooth, white, or gray, or buff ${ }^{15}$. According to Yadav et al. ${ }^{16}, 93.2 \%$ of the E. camaldulensis barks are organic (Table-1).

\section{TABLE-1}

CHEMICAL COMPOSITION OF E. camaldulensis BARKS ${ }^{16}$

\begin{tabular}{lc}
\hline Components & Dry weight of E. camaldulensis barks $(\mathrm{w} / \mathrm{w})$ \\
\hline Cellulose & 37.4 \\
Hemicellulose & 19.2 \\
Free sugars & 5.5 \\
Total carbohydrates & 62.2 \\
Lignin & 28.0 \\
Ash & 4.9 \\
Total nitrogen & 1.1 \\
Water extractables & 15.5 \\
Alcohol extractables & 7.2 \\
Total organic matter & 93.2 \\
\hline
\end{tabular}

E. camaldulensis barks were initially rinsed with distilled water followed by drying in the incubator under $105^{\circ} \mathrm{C}$. The dry barks were then ground to an average size of $1.21 \mathrm{~mm}$ using a pestle and a sieve.

Adsorbates: The dyestuffs, BV3 (C.I. Basic Blue 41) and AR360 (C.I. Acid Red 360), were obtained from a textile mill located nearby. Stock solutions of textile dyes were prepared using distilled water. BV3 and AR360 stock solutions were prepared using distilled water. Adsorption tests were conducted at $25^{\circ} \mathrm{C}$ in conical flasks $(250 \mathrm{~mL})$ using an orbital shaker operated at $400 \mathrm{rpm}$. The initial $\mathrm{pH}$ values were between 5.3 and 6.6 during the batch experiments and no $\mathrm{pH}$ adjustment was made throughout the study. One g (dry weight) of $E$. camaldulensis barks was added to each flask placed on the orbital shaker. The initial dye concentrations for the batch experiments were 20, 40, 80, 160 and $320 \mathrm{mg} / \mathrm{L}$, respectively. Contact times were 5, 10, 20, 40 and $80 \mathrm{~min}$ for BV3 and 5, 10, 20, 40, 80, 160 and $320 \mathrm{~min}$ for AR360.

Chemical analysis: After contacting, the contents of the conical flasks were centrifuged at $4000 \mathrm{rpm}$ for $10 \mathrm{~min}$ to separate the barks from the solution. The supernatants of BV3 and AR360 were then analyzed with a Baush-Lomb (spectronic 21) light spectrophotometer at 586 and $531.5 \mathrm{~nm}$ wavelengths, respectively, to determine the dye concentrations in the samples. Control experiments were also performed for each dye to measure any adsorption onto the glassware. Neither precipitation nor adsorption onto the walls of the flasks was observed. The results of dye analysis were used to calculate the specific adsorption, q (mg dye adsorbed/g barks, dry weight). All the experiments were duplicated and the results presented as mean values. The variation was $<5 \%$. $\mathrm{pH}$ measurement were done with $\mathrm{pH}$ meter (Hanna instrument pH 211 microprocessor $\mathrm{pH}$ meter). Considering the mass balance on the adsorbent, the amount of adsorbate sorbed, q, can be calculated as:

$$
\mathrm{q}=\frac{\left(\mathrm{C}_{0}-\mathrm{C}_{\mathrm{e}}\right) \mathrm{V}}{\mathrm{W}}
$$

where $\mathrm{C}_{\mathrm{o}}$ and $\mathrm{C}_{\mathrm{e}}$ are the initial and equilibrium concentrations of the dye in the aqueous phase, $\mathrm{V}$ is the volume of the aqueous phase and $\mathrm{W}$ is the amount of dry adsorbent $(\mathrm{g})$ consumed as calculated from the dry weight and water content of $E$. camaldulensis barks. All experiments were done in duplicates.

\section{RESULTS AND DISCUSSION}

Equilibrium: Experimental data show that there is a difference between the contact times required for optimum BV3 and AR360 removal and the amount of dye adsorbed per time. It can be seen from the results that the uptake rate of the tree barks increased with time, though not indefinitely. The adsorption rates of both dyes changed with the contact time where the adsorption rate was higher in the early stages and continuously decreased until the adsorption reached the plateau at around 20 minutes for BV3 and 80 minutes for AR360 (Fig. 1).

Amount of dye adsorbed when the equilibrium was reached reflects the optimum contact time of the $E$. camaldulensis barks in the removal of dyes. After varying contact times applied during the study the equilibrium times were found to be $20 \mathrm{~min}$ for BV3 and $80 \mathrm{~min}$ for AR360 for 

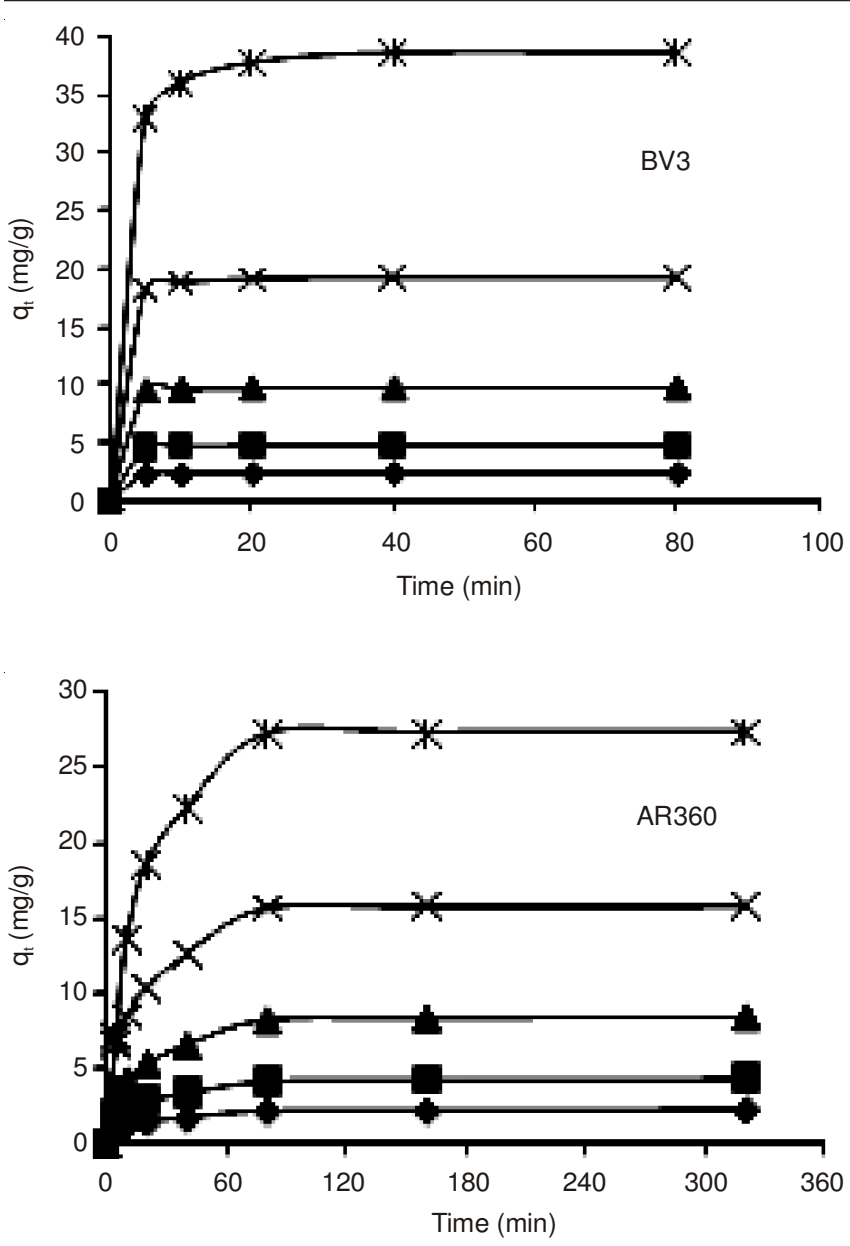

Fig. 1. Initial adsorption test results for BV3 and AR360 removal by $E$. camaldulensis barks

the concentrations of $20,40,80,160,320 \mathrm{mg} / \mathrm{L}$ (Fig. 1). The reason for the usage of varying dye concentrations was to determine the isotherms, the dimensionless constant separation factors and kinetics of the adsorbent/adsorbate system in addition to the determination of the equilibrium times for adsorption. According to the experimental results, it is clear that the removal rate increased with the increasing amount of dye after specified contact times. However, this process was limited up to $320 \mathrm{mg} / \mathrm{L}$ for both dyes. Throughout the experiments, it was observed that the dye concentration was an important factor for the adsorption rate up to certain concentration levels (Fig. 1). In Fig. 1 the pattern of the both curves (BV3 and AR360) are similar in the sense that the initial portion of the curve is smooth with almost a linear increase and then a plateau region is reached for both dyes. However, both curves differ from each other since they have different break points. The starting points of the plateau regions were at about 80 min for AR360 and 20 min for BV3. It can also be seen that the amount of BV3 adsorbed was higher than that of AR360 on the barks.

Isotherms: In order to determine the relationship between the tree barks and adsorption Langmuir, Freundlich, Temkin and Dubinin-Radushkevich adsorption isotherm models were used.

Equation (2) provided below represents the Langmuir isotherm ${ }^{17}$ :

$$
\frac{\mathrm{C}_{\mathrm{e}}}{\mathrm{q}_{\mathrm{e}}}=\frac{1}{\mathrm{~K}_{\mathrm{L}}}+\left(\frac{\mathrm{a}_{\mathrm{L}}}{\mathrm{K}_{\mathrm{L}}}\right) \mathrm{C}_{\mathrm{e}}
$$

where $\mathrm{C}_{\mathrm{e}}$ is the equilibrium concentration of adsorbate in solution after adsorption $(\mathrm{mg} / \mathrm{L}), \mathrm{q}_{\mathrm{e}}$ the equilibrium solid phase concentration $(\mathrm{mg} / \mathrm{g}), \mathrm{K}_{\mathrm{L}}$ and $\mathrm{a}_{\mathrm{L}}$ are the Langmuir constants. The Langmuir constants $\left(\mathrm{K}_{\mathrm{L}}\right.$ and $\left.\mathrm{a}_{\mathrm{L}}\right)$ were calculated and found positive for initial dye concentrations which indicate the adequacy of the isotherm models to explain the adsorption process. When $\mathrm{C}_{\mathrm{e}} / \mathrm{q}_{\mathrm{e}}$ data was plotted against $\mathrm{C}_{\mathrm{e}}$, good straight lines were obtained. The regression equations fit well at $99 \%$ significance level. The $\mathrm{Q}_{\max }$ (maximum adsorption capacity of adsorbent) values were found to be 40.98 and $37.59 \mathrm{mg} / \mathrm{g}$ for BV3 and AR360, respectively. The values of the Langmuir and Freundlich parameters summarized in Table- 2 indicate that the adsorption may occur favourably at $\mathrm{pH}$ 5.4-6.6 for BV3 and pH 5.3-5.9 for AR360 experiments. Considering the Langmuir constant, $\mathrm{Q}_{\max }$, which is a measure of the maximum adsorption capacity, it can be seen that the BV3 removal was higher than AR360 removal.

The Freundlich equation is an empirical equation employed to characterize heterogeneous systems defined by the heterogeneity factor, $1 / \mathrm{n}$. Therefore, the empirical equation can be written as:

$$
\mathrm{q}_{\mathrm{e}}=\mathrm{k}_{\mathrm{f}} \mathrm{C}_{\mathrm{e}}^{1 / \mathrm{n}}
$$

Linearized form of the Freundlich equation is as follows:

$$
\log \left(q_{e}\right)=\log k_{f}+(1 / n) \log C_{e}
$$

here, $\mathrm{k}_{\mathrm{f}}$ and $\mathrm{n}$ are constants that incorporate all factors affecting the adsorption process ${ }^{18}$. Here, $n$ indicates the degree of favourability of adsorption. The constant, $\mathrm{n}$, should have values in the range of 1 to 10 as a degree for the favourability of adsorption. A smaller value of $1 / \mathrm{n}$ indicates a stronger bond between adsorbate and adsorbent, while a higher value for $\mathrm{k}_{\mathrm{f}}$ indicates that the rate of adsorbate removal is high ${ }^{19}$. The values for the Freundlich isotherm constants show the adequacy of the isotherm models to explain the adsorption process. According to the regression equations, the regression coefficients $\left(\mathrm{R}^{2}\right)$ for BV3 and AR360 were 0.9989 and 0.9915 with correlation coefficients (R) 0.9994 and 0.9957 , respectively. Based on the Freundlich constant, $\mathrm{k}_{\mathrm{f}}$, which is a measure of the adsorption capacity of an adsorbent/adsorbate system, it can be seen that the BV3 and AR360 adsorption capacities $\left(\mathrm{Q}_{\max }\right)$ of E. camaldulensis are similar as seen in Table-2. For comparison, the $\mathrm{Q}_{\max }, \mathrm{k}_{\mathrm{f}}$ and $\mathrm{n}$ values obtained for other adsorbents from other studies cited in the literature were also provided and compared with those of the current study.

Table-2 shows that the performance of E. camaldulensis was comparable with that of other adsorbents for various dyes. According to the table, BV3 and AR360 adsorption isotherm constants of $E$. camaldulensis barks were not higher than some listed. Even though the adsorption capacities for the materials studied in the present work were lower than those for materials used in several previous studies, the possible use of $E$. camaldulensis barks for the tertiary treatment of wastewaters containing BV3 and AR360 could have the several advantages. For instance, E. camaldulensis is a common plant and found abundantly in/around various areas such as wetlands, rivers and lakes throughout the year. Beside this, it does not require any processing whereas the materials used in various studies 
TABLE-2

COMPARISON OF MAXIMUM ADSORPTION CAPACITY, $\mathrm{Q}_{\max }(\mathrm{mg} / \mathrm{g})$, OF VARIOUS ADSORBENTS FOR DYES

\begin{tabular}{|c|c|c|c|c|c|c|}
\hline \multirow{2}{*}{ Adsorbent } & \multirow{2}{*}{ Dye } & \multicolumn{2}{|c|}{ Langmuir constants } & \multicolumn{2}{|c|}{ Freundlich constants } & \multirow{2}{*}{ Ref. } \\
\hline & & $\mathrm{Q}_{\max }$ & $a_{L}$ & $\mathrm{k}_{\mathrm{f}}$ & $\mathrm{n}$ & \\
\hline \multirow[t]{2}{*}{ E. camaldulensis } & BV3 & 40.98 & 1.83 & 18.44 & 2.26 & Current study \\
\hline & AR360 & 37.60 & 0.02 & 1.53 & 1.52 & Current study \\
\hline PAAC* & BV3 & 60.42 & 1.05 & NDA & NDA & 5 \\
\hline SAAC* & BV3 & 85.84 & 0.86 & NDA & NDA & 5 \\
\hline Bentonite & MO & 34.34 & 7.21 & 5.25 & 1.40 & 20 \\
\hline Marine Alga & CR & 71.46 & 0.01 & 2.74 & 1.67 & 21 \\
\hline Coir pith & $\mathrm{RB}$ & 55.54 & 0.05 & 2.19 & 1.06 & 22 \\
\hline \multirow[t]{2}{*}{ Sawdust } & BV3 & 37.83 & 0.68 & 14.34 & 1.69 & 22 \\
\hline & $\mathrm{RB}$ & 17.35 & 0.05 & 1.98 & 2.08 & 22 \\
\hline \multirow[t]{2}{*}{ Sugarcane fiber } & BV3 & 10.44 & 0.61 & 4.73 & 4.76 & 22 \\
\hline & $\mathrm{RB}$ & 15.98 & 0.04 & 1.53 & 2.00 & 22 \\
\hline Fungus & MB & 185.2 & 0.03 & NDA & NDA & 23 \\
\hline Seed coat & MB & 176.9 & NDA & 78.06 & 3.10 & 24 \\
\hline Amberlite & BY28 & 14.90 & 0.18 & 3.30 & 0.46 & 25 \\
\hline Wheat bran & BY21 & 92.16 & 0.02 & 2.74 & 2.95 & 26 \\
\hline Hard wood & BB41 & 88.70 & 0.11 & 34.3 & 5.05 & 27 \\
\hline Linseed cake & BB41 & $407.70-573.00$ & NDA & NDA & NDA & 28 \\
\hline Biodegradable wastes & BB41 & $77.00-164.00$ & NDA & NDA & NDA & 29 \\
\hline
\end{tabular}

(*Activated carbon prepared from male flowers of coconut trees using phosphoric acid and sulphuric acid and abbreviated as PAAC and SAAC, respectively)

listed in Table- 3 require some processing before they can serve as adsorbents. Moreover, the adsorption performances of some materials studied by other researchers are dependent on various external/operational factors such as $\mathrm{pH}$, particle size and temperature.

On the other hand, the experimental data were also examined using the linearized form of the Temkin isotherm model given below in equation $(6)^{30}$ :

$$
\mathrm{q}_{\mathrm{e}}=\frac{\mathrm{RT}}{\mathrm{bT}} \ln \mathrm{K}_{\mathrm{T}}+\frac{\mathrm{RT}}{\mathrm{b}_{\mathrm{T}}} \ln \mathrm{C}_{\mathrm{e}}
$$

where $1 / b_{\mathrm{T}}$ corresponds to the adsorption potential of the adsorbent and $\mathrm{K}_{\mathrm{T}}$ is the Temkin isotherm constant $(1 / \mathrm{g})$. Using eqn. (6) it was possible to calculate the Temkin adsorption potential, $\mathrm{K}_{\mathrm{T}}$, of E. camaldulensis barks for BV3 and AR360 and the Temkin constant, $\mathrm{b}_{\mathrm{T}}$, related to the adsorption heat of the BV3 and AR360 molecules. These values are also listed in Table-3.

Another model employed for estimating the characteristic porosity and apparent free energy of adsorption was that of Dubinin and Radushkevich. The linearized form of the Dubinin-Radushkevich equation is given in eqn. $(7)^{31}$ :

$$
\ln \mathrm{q}_{\mathrm{e}}=\ln \mathrm{X}_{\mathrm{m}}-\mathrm{K}_{\mathrm{DR}} \varepsilon^{2}
$$

where $K_{D R}$ is related to the free energy of adsorption and $X_{m}$ is the Dubinin-Radushkevich isotherm constant related to the degree of sorbate adsorption by the biomass surface. The initial value of $\varepsilon$ was found using eqn. (8) as expressed below and this value was then incorporated into eqn. (7) to determine the values of $\mathrm{K}_{\mathrm{DR}}$ and $\mathrm{X}_{\mathrm{m}}$. These are also tabulated in Table-3.

$$
\varepsilon=\mathrm{RT} \ln \left(\frac{\mathrm{C}_{0}}{\mathrm{C}_{\mathrm{e}}}\right)
$$

For $E$. camaldulensis, the porosity factor, $\mathrm{K}_{\mathrm{DR}}$, for the plant biomass towards the BV3 and AR360 were found to be 0.0114 and 0.1047 , respectively. Values of $\mathrm{K}_{\mathrm{DR}}$ less than unity imply that the use of E. camaldulensis biomass for the removal of BV3 and AR360 may require several cycles to reduce the dye concentration below the desired level. Confirmation of the isotherm model was obtained by plotting $\ln \mathrm{q}_{\mathrm{e}}$ versus $\varepsilon$ when the data points yielded a straight regression line. The corresponding listed values of $\mathrm{K}_{\mathrm{DR}}$ and $\mathrm{X}_{\mathrm{m}}$ for the E. camaldulensis

\begin{tabular}{|c|c|c|c|}
\hline \multicolumn{4}{|c|}{$\begin{array}{c}\text { TABLE-3 } \\
\text { SUMMARY OF ISOTHERM PARAMETERS AND } \\
\text { REGRESSION COEFFICIENTS }\left(R^{2}\right)\end{array}$} \\
\hline \multirow{2}{*}{ Isotherms } & \multirow{2}{*}{ Parameters } & \multicolumn{2}{|c|}{ Dyes } \\
\hline & & BV3 & AR360 \\
\hline \multirow[t]{3}{*}{ Langmuir 1} & $\mathrm{q}_{\max }$ & 40.81 & 37.73 \\
\hline & $\mathrm{K}_{\mathrm{L}}$ & 1.801 & 0.026 \\
\hline & $\mathrm{R}^{2}$ & 0.9758 & 0.9800 \\
\hline \multirow[t]{3}{*}{ Langmuir 2} & $\mathrm{q}_{\max }$ & 14.06 & 20.20 \\
\hline & $\mathrm{K}_{\mathrm{L}}$ & 19.75 & 0.065 \\
\hline & $\mathrm{R}^{2}$ & 0.9279 & 0.9813 \\
\hline \multirow[t]{3}{*}{ Langmuir 3} & $\mathrm{q}_{\max }$ & 23.64 & 30.73 \\
\hline & $\mathrm{K}_{\mathrm{L}}$ & 9.174 & 0.037 \\
\hline & $\mathrm{R}^{2}$ & 0.5163 & 0.8345 \\
\hline \multirow[t]{3}{*}{ Freundlich } & $\mathrm{K}_{\mathrm{f}}$ & 18.498 & 1.528 \\
\hline & $\mathrm{n}$ & 2.268 & 1.526 \\
\hline & $\mathrm{R}^{2}$ & 0.9987 & 0.9926 \\
\hline \multirow[t]{3}{*}{ Temkin } & $\mathrm{K}_{\mathrm{T}}$ & 65.207 & 0.284 \\
\hline & $\mathrm{b}_{\mathrm{T}}$ & 0.443 & 0.484 \\
\hline & $\mathrm{R}^{2}$ & 0.8906 & 0.9273 \\
\hline \multirow{3}{*}{$\begin{array}{c}\text { Dubinin- } \\
\text { Radushkevich }\end{array}$} & $\mathrm{K}_{\mathrm{DR}}$ & 0.0114 & 0.1047 \\
\hline & $X_{m}$ & 109.87 & 75.754 \\
\hline & $\mathrm{R}^{2}$ & 0.9955 & 0.9725 \\
\hline
\end{tabular}
data indicate that the regression coefficient $\left(\mathrm{R}^{2}\right)$ for the Dubinin-Radushkevich isotherm was high (0.9955).

It will be seen from the data recorded in Table-3 for $E$. camaldulensis that the value of the regression coefficient for 


\begin{tabular}{|c|c|c|c|c|c|c|c|}
\hline \multicolumn{8}{|c|}{$\begin{array}{c}\text { TABLE-4 } \\
\text { RATE CONSTANTS FOR EACH DYE }\end{array}$} \\
\hline Dyes & $\begin{array}{l}\text { Conc. } \\
(\mathrm{mg} / \mathrm{L})\end{array}$ & $\begin{array}{c}\text { Lagergren rate } \\
\text { constants }(\mathrm{k})\left(\mathrm{min}^{-1}\right)\end{array}$ & $\mathrm{R}^{2}$ & $\begin{array}{c}\text { Second order constants }\left(\mathrm{k}_{1}\right) \\
(\mathrm{g} / \mathrm{mg} \mathrm{min})\end{array}$ & $\mathrm{R}^{2}$ & $\begin{array}{c}\text { Pseudo Second order } \\
\text { constants }\left(\mathrm{K}^{\prime}\right)(\mathrm{g} / \mathrm{mg} \mathrm{min})\end{array}$ & $\mathrm{R}^{2}$ \\
\hline \multirow{5}{*}{ BV3 } & 20 & 0.3710 & 0.8186 & 1.659 & 0.948 & 3.409 & 0.9998 \\
\hline & 40 & 0.4044 & 0.8595 & 1.696 & 0.9961 & 2.035 & 0.9999 \\
\hline & 80 & 0.4256 & 0.8381 & 0.7249 & 0.9879 & 1.343 & 0.9999 \\
\hline & 160 & 0.4113 & 0.9243 & 0.3153 & 0.9685 & 0.4 & 0.9998 \\
\hline & 320 & 0.3077 & 0.9639 & 0.0548 & 0.9623 & 0.066 & 0.9982 \\
\hline \multirow{5}{*}{ AR360 } & 20 & 0.0341 & 0.8346 & 0.0389 & 0.9581 & 0.0628 & 0.9747 \\
\hline & 40 & 0.035 & 0.8523 & 0.0223 & 0.98 & 0.0368 & 0.979 \\
\hline & 80 & 0.0357 & 0.9176 & 0.0115 & 0.9914 & 0.0154 & 0.9728 \\
\hline & 160 & 0.0363 & 0.9187 & 0.0062 & 0.9934 & 0.00817 & 0.975 \\
\hline & 320 & 0.0421 & 0.9598 & 0.0043 & 0.9976 & 0.00335 & 0.9663 \\
\hline
\end{tabular}

the Freundlich equation was higher than those for the Langmuir, Temkin, Dubinin-Radushkevich and Kiselev isotherms. Hence the Freundlich equation as expressed in equation (5) represents a better fit for the experimental data than the other isotherm equations.

Kinetics: If the movement of the solute from the bulk liquid film surrounding the adsorbent is ignored, the adsorption process for porous solids can be separated into three stages; mass transfer (boundary layer diffusion), sorption of ions onto sites and Intraparticle diffusion (pore diffusion). External mass transfer can be characterized by the initial rate of solute adsorption. This can be calculated from the initial slope of the curves plotted for $\mathrm{C}_{\mathrm{t}} / \mathrm{C}_{\mathrm{o}} v s$. time at initial dye concentrations of $80 \mathrm{mg} / \mathrm{L}$. These slopes can be derived by assuming that the relationship was linear over the first 5-10 $\mathrm{min}^{28}$. According to this approach, the slopes of BV3 and AR360 were derived by assuming that the relationship is linear over the first $10 \mathrm{~min}$. This approach provided initial rates of 0.0051 and 0.0025 for BV3 and AR360, respectively.

When a natural or synthetic material is to be considered as an adsorbent, the adsorption kinetics is always a significant issue in assessing the adsorption potential of any material. In a batch reactor with rapid stirring, there is also a necessary consideration that the transportation of adsorbate ions from solution into the pores of the adsorbent is the rate controlling step ${ }^{13}$. In order to determine the rate constant for intra-particle diffusion, the necessary equation was given by Weber and Morris ${ }^{32}$ :

$$
\mathrm{q}=\mathrm{k}_{\mathrm{id}} \mathrm{t}^{0.5}
$$

where $k_{\text {id }}$ values were obtained from the slopes of the linear portions of the plots for q versus $\mathrm{t}^{0.5}$ for each initial concentration. When the dye adsorption data for the tree barks are considered and applied to Weber-Morris equation provided above, it can be understood that the dye adsorption follow intra-particle diffusion. In order to show to the rate constant for intraparticle diffusion $\left(\mathrm{k}_{\mathrm{id}}\right)$ of the dyes into the barks, $80 \mathrm{mg} / \mathrm{L}$ initial concentrations was selected for each dye. Calculated $\mathrm{k}_{\text {id }}$ value of BV3 is not advisable. On the other hand, the $\mathrm{k}_{\text {id }}$ values of AR360 at $80 \mathrm{mg} / \mathrm{L}$ initial concentration were found

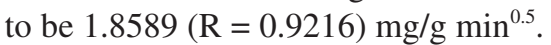

In many cases, the kinetics of adsorption by any biological material has been only tested for the first-order expression given by Lagergren. However, it has also been shown that a pseudo second-order approach can sometimes provide a better description of the adsorption kinetics ${ }^{33}$. The first-order Lagergren equation is:

$$
\frac{\mathrm{dq}}{\mathrm{dt}}=\mathrm{k}_{1}\left(\mathrm{q}_{\mathrm{e}}-\mathrm{q}_{\mathrm{t}}\right)
$$

where $\mathrm{q}_{\mathrm{e}}$ is the mass of metal adsorbed at equilibrium ( $\mathrm{mg} / \mathrm{g}$ ), $\mathrm{q}_{\mathrm{t}}$ the mass of metal adsorbed at time $\mathrm{t}(\mathrm{mg} / \mathrm{g})$, $\mathrm{k}$ is the firstorder reaction rate constant of adsorption $\left(\mathrm{min}^{-1}\right)$. The integrated form of eqn. 10 is:

$$
\log \left(\mathrm{q}_{\mathrm{e}}-\mathrm{q}_{\mathrm{t}}\right)=\log \mathrm{q}_{\mathrm{e}}-\frac{\mathrm{k}}{2.303} \mathrm{t}
$$

The second-order rate equation is:

$$
\frac{1}{\left(\mathrm{q}_{\mathrm{e}}-\mathrm{q}_{\mathrm{t}}\right)}=\frac{1}{\mathrm{q}_{\mathrm{e}}}+\mathrm{k}_{1} \mathrm{t}
$$

The pseudo second-order equation is:

$$
\frac{\mathrm{t}}{\mathrm{q}_{\mathrm{t}}}=\frac{1}{\mathrm{Kq}_{\mathrm{e}}^{2}}+\frac{\mathrm{t}}{\mathrm{q}_{\mathrm{e}}^{2}}
$$

where, $\mathrm{K}^{\prime}$ the pseudo second-order rate constant of adsorption ( $\mathrm{g} / \mathrm{mg} \mathrm{min}$ ). The results prove that the first and second order equations were generally suitable for all data. On the other hand, the regression coefficients of the first and second order reaction models were lower than that of the pseudo secondorder reaction model. For instance, the application of the pseudo second-order model produced the best fit for BV3 data. However, the regression coefficient of second order reaction model was higher than that of the pseudo second-order reaction model for AR360 data. The values of the reaction rate constants and regression coefficients for each dye are listed in Table-4.

\section{Conclusion}

In this study, it was observed that both dyes can be adsorbed by E. camaldulensis barks. E. camaldulensis barks were able to remove BV3 and AR360 from aqueous solutions within contact times of 20 and 80 minutes, respectively. Regarding the contact time, AR360 adsorption was found to be slower as compared to BV3. Langmuir, Freundlich and Dubinin-Radushkevich adsorption isotherm constants indicated the adequacy of the isotherm models to explain the adsorption process. Since the determined $\mathrm{R}_{\mathrm{L}}$ values are between 0 and 1 , the adsorption of both dyes on E. camaldulensis is attainable. Although slow adsorption rate of AR360 were observed, the comparison of Qmax values obtained in this study with those of other studies indicates considerable adsorption capacity by E. camaldulensis. The kinetics of the system and the data indicated that the adsorption kinetics of AR360 fit the intra-particle diffusion. However, adsorption of 
BV3 was fast and completed in 5-10 min. The results show that the application of $E$. camaldulensis barks for the tertiary treatment of dye-containing wastewaters is feasible for full-scale applications.

\section{REFERENCES}

1. V. Prigione, V. Tigini, C. Pezzella, A. Anastasi, G. Sannia and G.C. Varese, Water Res., 42, 2911 (2008).

2. Anon, Profile of the Textile Industry, Office of Compliance Sector Notebook Project (EPA/310-R-97-009), Environmental Pollution Agency. Washington DC, USA, (1997).

3. J.F. Kouba and P. Zhuang, Fluid/Particle Sep. J., 7, 87 (1994).

4. G. McKay, M. Otterburn and J. Aga, Water, Air Soil Pollut., 24, 307 (1985).

5. S. Senthilkumaar, P. Kalaamani and C.V. Subburaam, J. Hazard. Mater, B136, 800 (2006).

6. B.H. Hameed, D.K. Mahmoud and A.L. Ahmad, J. Hazard. Mater. 158, 65 (2008)

7. Mittal, V.K. Gupta, A. Malviya and J. Mittal, J. Hazard. Mater., 151, 821 (2008).

8. H.B. Crawford and C. Gretlyn, Water Treatment Plant Design, 2nd Edn., American Society of Civil Engineers/American Water Works Association. McGraw-Hill. New York (1990)

9. T. Asano, Wastewater Reclamation and Reuse, Water Quality Management Library, Technomic Publishing Company. Lancaster. PA, USA, vol. 10 (1998)

10. Y.C. Wong, Y.S. Szeto, W.H. Cheung and G. McKay, Process Biochem., 39, 695 (2004)

11. G. Tchobanoglous, Wastewater Engineering, Treatment, Disposal and Reuse (Metcalf \& Eddy), McGraw-Hill. New York, edn. 4 (2003)

12. W.W. Eckenfelder, Industrial Water Pollution Control, McGraw-Hill International Editions, New York, (1989).
13. L.C. Morais, O.M. Freitas, E.P. Gonçalves, L.T. Vasconcelos and C.G.G. Beça, Water Res., 33, 979 (1999)

14. G. Palma, J. Freer and J. Baez, Water Res., 37, 4974 (2003).

15. E.L. Jr. Little, Common Fuelwood Crops: a Handbook for their Identification. McClain Printing Co. Parsons WV (1983).

16. K.R. Yadav, R.K. Sharma and R.M. Kothari, Biores. Tech., 81, 163 (2002).

17. I. Langmuir, J. Am. Chem. Soc., 40, 1361 (1918).

18. H. Freundlich, Colloid and Capillary Chemistry, Methuen, London, p. 883 (1926)

19. B. Noroozi, G.A. Sorial, H. Bahrami and M. Arami, J. Hazard Mater, 139, 167 (2007).

20. E. Erdal, Clean, 38, 758 (2010)

21. X.S. Wang and J.P. Chen, Clean, 37, 793 (2009).

22. C. Namasivayam, M.D. Kumar, K. Selvi, R.A. Begum, T. Vanathi and R.T. Yamuna, Biomass Bioenergy, 21, 477 (2001)

23. Z. Aksu and E. Balibek, J. Environ. Man., 91, 1546 (2010).

24. Z. Yao, L. Wang and J. Qi, Clean, 37, 642 (2009).

25. J. Yener, T. Kopac, G. Dogu and T. Dogu, J. Colloid Interf. Sci., 294, 255 (2006)

26. M.T. Sulak, E. Demirbas and M. Kobya, Biores. Tech., 98, 2590 (2007).

27. H.M. Asfour, M.M. Nassar, O.A. Fadali and M.S. El Geundi, J. Chem. Tech. Biotech., 35A, 28 (1985).

28. R.M. Liversidge, G.J. Lloyd, D.A.J. Wase and C.F. Forster, Process Biochem., 32, 473 (1997).

29. M.P. Elizalde Gonzalez and A. Pelaez, Environ. Tech., 24, 821 (2003).

30. M. Temkin and V. Pyzhe, Acta Physicochim. URSS., 12, 327 (1940).

31. M.H. Horsfall Jr and A.I. Spiff, Acta Chim. Slov., 52, 174 (2005).

32. W.J. Weber and J.C. Morris, J. Sanit. Eng. Div. Am. Soc. Siv. Eng., 89, 31 (1963).

33. C.W. Cheung, C.F. Porter and G. McKay, Sep. Purif. Technol., 19, 55 (1997). 